\title{
Analysis of the performance of public policies in Brazil to cope with sexual violence against children and adolescents
}

\author{
COSTA, Andréa de Araújo * \\ * https://orcid.org/0000-0002-0673-1256 \\ Candidate for the Masters in Law at Univertity Center of Brasília - UniCEUB - Brazil \\ emails: andrea.araujo@sempreceub.com or andcosta1981@gmail.
}

2021, may

\begin{abstract}
This article presents an analysis of the confrontation of the State to act against sexual violence against children and adolescents, with a common name to the terms children and adolescents, with the objective of discussing public policies. Efforts are concentrated on the legal and regulatory aspects for sustainability and implementation of public policy programs in the Brazilian state. Initially, consideration was given to the definitions and concepts of public policies based on the main doctrines and researchers on the topic, such as Wildasky (1979); Maria Paula Bucci (2006), guidelines for making political decisions are added in the structuring and formulation of concrete actions, as indicated by Enrique Saraiva (2006). Then, it dialogues with the list of the main public policies arising from the action of the Brazilian state, listing the main ones: Statute of the Child and Adolescent (ECA) through Law No. 8,069 of July 13, 1990; the creation of the National Council for the Rights of Children and Adolescents (CONANDA) in 2000, among other programs in the following years, including the National Plan to Combat Child and Youth Violence (PNEVSCA), the Integrated Actions Program and References for Confronting Child and Youth Violence in the Brazilian Territory (PAIR) and the Sentinela Program, which constituted a set of social assistance measures to assist children and adolescents who are victims of sexual exploitation. In addition, it discussed the international conventions adopted by the United Nations (UN) for the rights of children and adolescents, as well as considerations about the indicators of sexual violence against them. Finally, it was concluded that the National Plan to Combat Violence against Children and Adolescents in the Brazilian case was important as a policy outlined and implemented in its different phases as a cycle of public policies, and that despite the progress, the current perspectives are outlined by the state as incipient and without the necessary resources as required. In this sense, the state's policy focuses precisely on responding to various situations of violence in the context of social vulnerability.
\end{abstract}

Keywords: Public Policies. Confronting Violence against Children and Adolescents. Software.

$\dagger$ Acknowledgments: Thanks to colleagues for the discussion and debate on this topic and to Professor Doctor Frederico Barbosa for his guidance in the Public Policies discipline of the postgraduate program in the Master's in Law at the University Center of Brasilia - UniCEUB, Brasília, DF. In particular, to Professor of Federal University Piauí/Brazil, Doctor Rogério Ferreira dos Santos for reading and preliminary review of this text. 


\section{INITIAL CONSIDERATIONS}

The main objective of this article is to discuss public policies to confront sexual violence against children and adolescents in Brazil. The relationship between State, Society and law is evident. Being also interdependent, it is no longer possible to think of the legal system as a closed body of rules, with coercive and mandatory rules capable of organizing and determining the conduct of citizens.

Seen in this light, it can be said that the structuring of society is based on a new paradigm, the systems paradigm. A complex system, since it is made up of several other subsystems, but which complement and complete each other when the objectives are aimed at a certain end, within an expanded sphere, as an initial view of the State and society. All these changes in the vision of the State provide all those involved with a favorable environment for relations to become stronger, more meaningful and more conscious. Learning that goes from being merely personal to becoming social. Thus, society seeks, through its components, to structure public policies, which should be able to meet and correspond to the needs and expectations of citizens, thus triggering structural changes.

Analyzing this approach, this article seeks to unfold the performance of public policies for children and adolescents in the context of sexual violence against children and adolescents. Becoming also an objective in the study on screen, to raise a reflection on the importance of the performance of public policies in cases of sexual abuse of children and adolescents. Due to what has been explained here by other researchers mentioned, this is a phenomenon difficult to be faced by everyone, as it is an action that involves victim and aggressor, making it necessary to have a fine and interdisciplinarity, with the purpose of to have the guarantee of legislative punishment.

Intrafamily sexual abuse of minors is currently one of the public policy priorities of many governments in western democratic countries. This fact is mainly due to the increase in denunciations of this type of practice, which is normally considered reprehensible when it is not a true crime, in legal terms against the person of the minor.

In fact, both in ethical and legal codes, there are references to rights and duties, norms and moral principles considered fundamental and directing for this scope, including within the intrafamily scope, such as protection of the dignity and or vulnerability of the human person, respect the full / partial autonomy of the people involved in the act. The actions of the groups that have been working with the intent to prevent and unveil sexual abuse in minors in the family, and that create strategies and mechanisms capable of avoiding impunity; they encounter difficulties due to the practice of silence by the victims and society in general.

Studies have exhaustively demonstrated that sexual violence against children and adolescents occurs in all social strata ${ }^{1}$, it is not limited to a certain ethnicity or creed, it does not depend on political and economic regimes, it can reach children and adolescents in all age groups inside and outside the environment famil$\operatorname{iar}^{2}$ and its frequency is much higher than estimated Bittencourt.

From a social point of view, it points to the fragility and inefficiency of the legislative, judicial and educational, social assistance and health systems in promoting and providing children and adolescents with the protection due to them. ${ }^{3}$

Only in the last three decades has the debate on sexual violence against children and adolescents gained greater visibility on the part of government agencies, civil entities and non-governmental organizations in the country and in the world.

\section{Public Policies: definitions and concepts}

In order to understand the role of the state ${ }^{4}$ in the formulation of public policies, it is important to base the concept and its history over centuries on the time, Brucci ${ }^{5}$ being explained as a starting point. Since the author dedicated himself to translating the various existing conceptions in relation to the time and the reasons that determined its emergence. The idea of public policy is somewhat complex, as it is not a complete and defined theory on the subject, but several concepts that form it (which can be translated as public policies.

The theme of public policy has been built and perfected since the 1930s of the 20th century, through the contribution of several authors Lasswell, 1936; Simon, 1957; Lindblom, 1959, Easton, 1965; Lynn,

1 GAUDERER, E. C.; MORGADO, K. (1992). Sexual abuse in children and adolescents. Journal of Pediatrics. Porto Alegre, vol. 68, n. 7/8, p. 243-247.

2 AZEVEDO, M. A. (1998). Psychological consequences of the victimization of children and adolescents. In: AZEVEDO, M. A; Guerra, V.N.A (Org.). Victimized children: the small power syndrome. São Paulo: Iglu p. 143-167.

3 CHILD WELFARE INFORMATION GATEWAY (2003). Emerging practices in the prevention of child abuse and neglect. Washington DC.: Office on child Abuse and Neglec. Available at http://www.childwelfare.gov/preventing/programs/what works/report/emerginga.cfm Accessed on: December 14th. 2007.

4 It should be noted that the term state comes from the Latin status, which means position and order. For Bobbio this term gained notoriety for the prestige of the work $\mathrm{O}$ Príncipe de Machiavelli.

5 BUCCI, M. P. Dallari (2006). Public Policies. Reflections for a legal concept, Ed. Saraiva. Santos: UNISANTOS, SP.

Analysis of the performance of public policies in Brazil to cope with sexual violence against children and adolescents 
80; Peters, 1986, Mead, 1995. ${ }^{6}$ As Ham and Hill, 1993 , citing Wildasky 1979, clarify, public policy does not refer only to the process of policy making, decision making, since, at the same time, it is also a product of this process. ${ }^{7}$

In this sense, Maria Paula Dallari Bucci, clarifies that:

Public policy is the governmental action program that results from a set of legally regulated processes - electoral process, planning processes, government process, budget process, legislative process, administrative process, judicial process, aiming to coordinate the means available to the state and private activities, for the achievement of socially relevant and politically determined objectives. $^{8}$

For Enrique Saraiva:

It is a flow of public decisions, aimed at maintaining social balance or introducing imbalances aimed at changing this reality. Decisions conditioned by the flow itself and by the reactions and changes that they may cause in the social fabric, as well as by the values, ideas and views of those who adopt or influence the decision. It is possible to consider them as strategies that point to different ends, all of them in some way, desired by the different groups that the theory of public policy participates in the decision-making process. ${ }^{9}$

It is important to emphasize, initially, that public policy does not refer only to issues that involve its formulation, that is, from the consequences of the application of resources, its legal aspects, legitimacy or just as an attribute of the state.

It is also necessary to debate its historicity, the emergence of ideas as well as the authors involved, after all it is the relationship between actors such as the state, social classes, and civil society ${ }^{10}$ that arise the agents who are able to define public policies.In addition, as Dias and Matos well observe, stating that cooperation between the authors involved in a

6 However, they are considered the founders of Lasswell (19021978), Senior (1916-2001) Lindblom (1917) and Easton (1917). It should be noted that the study of public policies was born in the USA, in the 1930s (SOUZA, 2006).

7 HAM, Cristopher; HILL, Michael (1993). The policy making process in the modern capitalist state ( $\mathrm{R}$. Amorim; R. Dagnino, Trad.). Adaptation and revision: Renato Dagnino. Campinas- SP: Editora da Unicamp.

8 BUCCI, Maria Paula Dalllari. (2006) The concept of Public Policies in Law. In: Public Policies: reflections on the legal concept. São Paulo: Saraiva, p. 1-50, p.39.

9 SARAIVA, Enrique (2006). FERRAREZZI, Elizabete (Org.). Public policy. Brasília: ENAP. Available at: http//repositório.enap.gov.br/bitstream/handle/1/1254/ saravia.pdf. Accessed on 02/14/2017.

10 As well explained by BERNSTEIN, Brasil (1996). The structuring of class, code and control pedagogical discourse. Petrópolis: Editora Vozes. participatory and dialogical manner is essential in the process of implementing a given policy. ${ }^{11}$

Other authors emphasize the role of public policies in solving problems, but are criticized for overestimating rational and procedural aspects of public policies. In these perspectives they argue that theories ignore the essence of public policies, that is, the clash around ideas and interests. It can also be added that, by focusing the focus on the role of governments, these definitions put aside their conflicting aspect and the limits that surround government decisions, also leaving out the possibilities of cooperation that can occur between governments and other institutions of social groups.

Pinto ${ }^{12}$ complements that, according to the theory of the public policy cycle, the path followed begins with the elaboration of an agenda, in which interests and proposals are placed on the "table" of negotiations, defining preferences that are adapted to the governmental political project, following stages of formulation of proposals, choice of alternatives and implementation of public policies.

Saraiva addresses the phases or stages of public policy, signaling that:

(...) formulation, implementation and evaluation - need a certain degree of specification in Latin America. It is necessary, for example, to distinguish between formulation elaboration, the first is the preparation of the political decision, the second is the political decision, or the decision taken by a politician or by Congress, and its formalization through a legal norm. The implementation must also be detailed in Latin America. It is necessary to separate the implementation itself, which is preparation for execution, (or in other words, the preparation of plans, programs and projects) from execution, which is to put political decision into practice. This distinction is necessary, because each of the steps mentioned is a field for different types of negotiation. ${ }^{13}$

The three phases or steps mentioned above are of paramount importance for the consolidation of the various Brazilian public policies. We highlight the extreme need for both implementation and evaluation of public policy, in the context of combating the sexual violence of children and adolescents. Analyzing the structuring of these policies is one of the chal-

11 DIAS, Reinaldo; MATOS, Fernanda (2012). Public policies: principles, purposes and processes. São Paulo: Atlas.

12 PINTO, Isabella Cardoso de Matos (2008). Change in Public Policies: the perspectives of the public policy cycle. Public Policy Review. São Luís, v.12, n 1, p.27-36, jan./jul. Available at: http // www.periodicoeletronicos.ufma.br / index.php / Republi.

13 SARAIVA, Enrique (2006). FERRAREZZI, Elizabete (Org.). Public policy. Brasília: ENAP. Available at: http // repositório.enap.gov.br / bitstream / handle / 1/1254 / saravia.pdf /. Accessed on 02/14/2017. 
lenges in Brazil, given the difficulties in organizing and implementing programs to prevent child sexual abuse.

Clarice Duarte ${ }^{14}$ discusses in depth the public policy cycle, explaining that the process of defining and implementing public policies encompasses a series of distinct stages and activities, highlighting some, such as those presented below:

a) the implementation of the problems and demands to be tackled in order to define the priorities to be decided with the public policy makers;

b) formulation of concrete proposals among different program options to be adopted;

c) the actual implementation of the policy, with the creation of the necessary structure and observance of the existing bureaucracy, expenditure of resources and approval of the law;

d) evaluation of the results of the policy through the verification of the results and impact of the policy, so that one can really assess whether it works or not; e) inspection and control of the implementation of the policy through the actions of civil society, the Audit Courts and the Public Ministry.

The aforementioned author adds that these different phases mentioned above, do not occur in a linear fashion, but constitute a dynamic process, making it, as much as possible, useful to identify the peculiarities present in each stage that form the cycle of public policies. It is emphasized that the mastery of the theoretical model now analyzed "(...) facilitates its understanding, allowing the identification of omissions or inadequacies on the part of those who have a duty to implement the rights of which they are the object". 15

Also analyzing the challenge in the public policy evaluation phase Marilia Ramos and Leticia Schabbaach, they deal with published work on the state of the art in public policy evaluation, which in Brazil the growing interest of governments in evaluation is related to issues of effectiveness ( achievement of goals, gauging the expected and unexpected results of the program) or effectiveness for greater production, greater efficiency for efficiency, lower cost of production, greater efficiency for performance and accountability of public management.

At the academic level, studies in this area are proliferating, although greater attention is given to the processes of shaping the agenda and formulation of

\footnotetext{
14 DUARTE, Clarisse Seixas (2013). The Public Policy cycle. In: Bertolinni, Patrícia Tuma Martins; SMANIO, Gian Paulo Paggio. (Org.). Law and Public Policies in Brazil. Sao Paulo; Atlas, 2013, p.16-43. p.26. $15 \mathrm{Id}$.
}

public policies, to the detriment of implementation, evaluation and monitoring. ${ }^{16}$

When approaching and analyzing public policies and the conclusions presented by several authors, numerous researchers abandon their previous investigations to prove their hypotheses and methods, while observing the growing number of recurring theses of the conceptual apparatus available in matter. ${ }^{17}$

Therefore, the idea behind the adoption of a particular public policy is to make its implementation capable of generating changes in a given context, and it is necessary to understand the reasons that will lead to decision making. ${ }^{18}$ Public policy can also be approached as an instrumental process based on research.

It should also be noted that the division of the public policy making process into stages corresponds to an ideal type that will not always be observed in reality, demonstrating, therefore, that not every policy follows this linear process and can often extend for a long time. indefinite time. Since when trying to portray the domestic scope, the complexity that involves the elaboration of public policies through the institution of state bodies is evident, as well as its relationship with interest groups and the dilemmas of decision-making processes.

In addition, when we try to draw parameters between public policies and Programs to Combat Sexual Violence against children and adolescents, it should be noted that the period before $\mathrm{CF} / 88$ was decisive for changing paradigms in the area of guaranteeing women's rights. children and adolescents. The constitutional text brought the principles of integral protection of the rights of children and adolescents with absolute priority, with the theme of sexual violence having a special relevance.

The view of the "object child", the "younger child", that is, the hygienist and correctional view is replaced by the view of the child as subjects of rights. Brazil was the first country to enact a legal framework for the Statute of Children and Adolescents (ECA) in line with the 1989 Convention on the Rights of Children and Adolescents, from which a specific justice and security system was implemented for this purpose. children and adolescents, with the creation of Child

16 RAMOS, Marília Patta; SCHABBACH, Letícia Maria (2012). The state of the art of public policy evaluation conceptualization and examples of evaluation in Brazil. Journal of Public Administration, Rio de Janeiro., V. 46, n 5, p 1271-1294, sep/oct

17 SUREL, Ives. (2008). Public policies as paradigms Public Policies as Paradigms Political studies. Trad. Javier Sanchs Segura. Estudios Politicos, n 33, Medellin/Colombia, juliodiciembre de 2008, pp.41-65. ISSN 0121-5167.

18 FONSECA, Paulo Cesar Dutra; MONTEIRO, Sergio Marley Modesto (2008). The state and its reasons: The II PND. Political Economy Magazine. v. 28. N. 21. São Paulo, Jan / Mar.

Analysis of the performance of public policies in Brazil 
and Youth Courts, in addition to specialized police stations. At the international level, the world was already advocating the creation of plans to face sexual violence, in view of the Declaration and Agenda for Action approved at the First World Congress against commercial sexual exploitation of children, held in Stockholm in August 1996.

In the first decade of the 2000s, Brazil made significant progress in tackling violence against children and adolescents with the approval by the National Council for the Rights of Children and Adolescents (CONANDA) of national thematic policies, which led to the emergence of the National Plan Facing Sexual Violence against Children and Youth.

It becomes essential in the process of revising the National Plan to Combat Sexual Violence against Children and Adolescents in order to understand the real changes that impact the constant needs to update the regulations related to the theme as well as the guarantees of the human rights of children and adolescents.

For this purpose, the methodology designed for the revision of the 2013 National Plan as a public policy to accomplish this intent includes the compilation of national and international regulations on this theme, with the aim of affirming the basis of its guidelines within the context of legal definition and to present the international and national norms related to the rights of children, ${ }^{19}$ on the approach to confront sexual violence.

From the perspective of sexual abuse in childhood and adolescence of human rights, prevention, intervention and promotion actions for the subject's health must be carried out, as this social issue that implies subjectivity, however, implies in guaranteeing the rights established by the Statute of the Children and Adolescents (ECA).

\section{Dialoguing with public policies and child sexual abuse}

With the increasing expansion of the late twentieth century, it became necessary to introduce social problems that are discussed at international conferences. Multilateral conferences in this context started to develop solutions to the social problems in question, which starts to demonstrate the innovation of their approach, thus establishing relationships between the local, the national, and even the international.

In this dimension, matters that were previously restricted to domestic jurisdictions have acquired greater importance before the United Nations (UN).

\footnotetext{
19 This document refers to children, under the age of 18 , in accordance with the UN Convention on the Rights of the
} Child.
The World Summit on Children opened a discussion on child protection, so, then, the United Nations General Assembly adopted the convention, considered an instrument of international protection, where, according to the documents, "child is every minor individual 12 years old, and who have the right to life, free primary education, and protection against damage and neglect that must, thus, be guaranteed by the state, among others". ${ }^{20}$

The United Nations Convention on the Rights of the Child brought the concepts of separation, participation and responsibility as can be seen: "The concept of separation, here refers to a clear and necessary distinction, to begin at the normative level, of problems of a social nature, of those conflicts with the criminal law". 21

The co-responsibility principle deals with the provisions of the aforementioned article 22 of $\mathrm{CF} / 88$, as well as the caput of art. 4th of the ECA which establishes as follows:

\begin{abstract}
It is the duty of the family, the community, society in general, and the government to ensure, with absolute priority, the realization of the rights relating to life, health, food, leisure, sport, professionalization, dignity, respect, freedom and family and community coexistence. ${ }^{22}$
\end{abstract}

In this context, interests, like the child's priority, become a need to be ensured by everyone, especially state power. What was established to protect children and adolescents against situations of sexual exploitation resulted in the Protocol, which has obtained 67 ratification's so far, including Brazil, in 2004. ${ }^{23}$

According to the Protocol, it is intended to recommend actions that are for the signatory States for cases involving sexual exploitation. Therefore, the document highlights in its other articles the importance of adopting appropriate measures to protect the rights of the child, as well as pointing out the need to prevent these situations through the implementation of laws and public policies.

In general, social partners, reintegration measures, as well as the psychological and physical recovery of children who are victims of exploitation. It is worth mentioning that it is in this sense that public policies are now implemented in this scenario.

In Brazil, with the advent of the Child and Adolescent Statute (ECA), in line with the Convention on the

20 UNITED NATIONS ORGANIZATION (1989). Convention on the Rights of the Child, adopted on November 20.

21 Id.

22 BRAZIL (1990).Law n. 8,069 of July 13, 1990 the provides for the Statute of the Child and Adolescent (ECA). Brasília: National Congress.

23 The UN committee on the rights of the child is composed of experts responsible for monitoring the implementation of the Convention and its protocols. 
Rights of the Child (1989), it is estimated that ECA has inspired more than 15 legislative reforms. Based on the ECA, a specific justice and security system for children and adolescents was implemented, with the creation of the Childhood and Youth courts, in addition to specialized police stations.

In the wake of this movement, in 2000, the Optional Protocol to the Convention on the Rights of the Child referred to the sale of children, child prostitution and child pornography. ${ }^{24}$ Providing Brazil with a consolidated regulatory framework in relation to the protection of children's rights. children and adolescents, in addition to laws.

In the first decade of the 2000s, Brazil made significant progress in tackling violence against children and adolescents, with the approval by the National Council for the Rights of Children and Adolescents (CONANDA) of thematic public policies. At this moment, the National Plan for Confronting Sexual Violence against Children and Adolescents is emerging, which allows the country to experience a series of advances in the area of recognition and confrontation of sexual violence.

The plan also served as references for nongovernmental organizations, especially within the scope of social mobilization and the monitoring of public policies in the perspective of formulation and effective implementation of actions in this area by state spheres.

Another instrument, the National Plan for Confronting Child and Youth Violence (PNEVSCA), has the primary function of structuring policies to guarantee the rights of children and adolescents organized in 06 axes, namely: "analysis of the situation, mobilization and articulation, defense and accountability, care, prevention and protagonism for children and adolescents". 25

Public policies for combating sexual exploitation are coordinated by the PNEVSCA, the first two actions being the Integrated Actions and Referential Program to Combat Sexual Violence against Children and Youth in the Brazilian Territory (PAIR), launched in 2002 and the Sentinela Program, in force since 2001.

PAIR as a policy program creates and strengthens local networks through the integration of services with social participation, local operating plans and the training of teams in the municipalities in which it is present to form a protection network, in addition to the use of teaching platforms presence of national dissemination.

24 Adopted on May 25, 2000 and ratified by Brazil on January 27, 2004, - see Decree No. 5007, of March 8, 2004

25 BRAZIL (2013). National Plan to Combat Violence against Children and Adolescents. Brasília: Ministry of Human Rights, 2013.
Idealized within an intergovernmental management concept, the Sentinela Program of an intersectoral nature, has its guidelines and rules established in December 2001, through ordinance No. 878/2001, and its implementation started in 2002, under the responsibility of the extinct Secretariat of State of Social Assistance (SEAS), from the Ministry of Social Security and Assistance (Brazil, 2002).

The general objectives of SEAS are to assist, within the scope of the assistance policy, through an articulated set of actions, children and adolescents victimized by violence, emphasizing sexual abuse and exploitation, and to create conditions that enable victims and children and adolescents to their respective families the rescue of the guarantees of rights, access to services of social assistance, health, education, justice, leisure and culture.

The Sentinela Program has a set of social assistance measures to assist children and adolescents who are victims of sexual exploitation, as well as that of their families.

Created by the federal government in February 2003, as strategies to integrate programs and actions at the federal level, the main task of the Intersectoral Commission is to propose public policies for the eradication of violence, abuse and sexual and commercial exploitation of children and adolescents considered as serious violations of human rights, practiced throughout the national territory.

Since its creation, the Intersectoral Commission has played a fundamental role in articulating the spheres of government and integrating the actions of the federal government for the performance of public policies and the organization of civil society. twocolumn devem ser escritos no ambiente resumoumacoluna.

\section{90'S DECADE: the emergence of sexual vi- olence against children and adolescents as a public policy problem.}

We can conclude that the sexual violence of children and adolescents in Brazil, especially the sexual exploitation of children and adolescents, became a target in the political community when the issue started to be perceived as capable of causing political burdens or bonuses before the national and international community, either by omission or by the action of the State. We refer here to the Federal Constitution of 1988 and the United Nations Convention for the Rights of Children and Adolescents provided for in the 1990 ECA.

According to Art. 2 of the Statute of the Child and Adolescent, given that the child is the person up to 12 years of age as defined by the UN, Brazilian law recognizes that the child as a person in a peculiar con-

Analysis of the performance of public policies in Brazil to cope with sexual violence against children and adolescents 
dition of development, should be treated as a subject of legitimate and indivisible rights and that demands priority attention from society and the State.

The transition from the social question to the public policy problem, as differed by the creation formulated by Kingdom ${ }^{26}$, occurs through the influence of three basic mechanisms, namely: (1) events, crises and symbols, (2) indicators, and (3) feedbacks government actions.

The Youth Statute (EJ) approved by Law n ${ }^{\circ} 2.852$ / 2013 , determines what are the rights of young people that must be guaranteed and promoted by the Brazilian state and defines young people as aged between 15 and 29 years (paragraph 1 of the EJ). To adolescents aged 18 years, Law No. 8,069 of July 13, 1990 Statute of Children and Adolescents (ECA) is applied, when it does not conflict with the norms for full protection of adolescents (paragraph 2 of the EJ).

Events that took place in the 1990s promoted visibility to the theme of sexual violence against children and adolescents, both nationally and internationally. In Brazil, we can establish as a pioneer landmark of this political - media production, of the social visibility of the phenomenon.

In that decade, the work of the Parliamentary Commission of Inquiry (CPI) of the Chamber of Deputies was instituted in 1993, and also of the CPI of child prostitution, which inseminated the debate in several spheres by provoking the mobilization of sectors such as the executive, legislative and judiciary.

Important consequences of these CPIs were public opinion campaigns, which emerged around the mobilizations of the various social segments due to the growing complaints that proliferated. At the time, several states mobilized, including Bahia in 1995, taken over by the federal government that implemented the campaign to end exploitation, violence and sexual tourism in 2004 .

The civil and governmental organizations mobilized by this campaign have joined the End Children Prostitution, Child Pornography and Trafficking of Children for Sexual Purposes. ${ }^{27}$

In the 2000s, the PNEVSIJ, was an important reference for the analysis of this whole movement of institutionalization of the agenda to confront sexual violence against children and adolescents. In fact, the National Plan has become the official agenda of the public authorities (coordinated by the Human Rights Secretariat) and of the various forum of organized

26 KINGDON, John W (2011). Agendas, Alternatives and Public Policies. 2nd Edition (magazine). Boston: Longman.

27 BRAZIL (2004). Final Report of the Joint Parliamentary Commission of Inquiry on violence and sexual exploitation networks for children and adolescents in Brazil. Brasília: National Congress civil society under the management of the National Committee to Combat Violence.

In this same perspective in the public policy cycle, the moment of deliberation of the first version of the National Plan (2000) can be considered the peak in the decision-making phase, the culmination of the first period rich in formulations and choice of solutions to recognized problems. However, decisive processes of a decisive nature also occur when the actions of the plan start to materialize, because at that moment an ordering of priorities is evidenced, as well as definitions of actions that will actually be implemented, to the detriment of others, and that later will become be evaluated.

In the EVSCA policies, in view of the dynamics from which its different phases originated, involved in political debates, there is an interference of the authors who are in the direct management of the political programs and the political authorities in the different moments of decision making. What goes on to show a peculiar process of democratic participation of the different actors in the different phases of the cycle of this public policy.

Hence there is a total consonance with a tendency to make political decisions, in a context of policy networks ${ }^{28}$ in which the same approach forms policy communities, which integrate a set of political entrepreneurs, and who share common visions and purposes for a given policy. public. ${ }^{29}$

Therefore, the processes of implementation and formulation of public policies took place in the interaction between different authors involved, reducing a historical distance between the one who decides and the one who executes.

One of the first actions of the federal government itself after the approval of the first version of the PNEVSIJ, was the formulation of the Sentinela Program, at the end of the year 2000. And according to the National Plan, the program launched in December 2002, proposed the structuring of municipal specialized, multi professional and interdisciplinary services from a network perspective.

Implemented as technical support, the intervention of the Guardianship Councils in cases of domestic violence and sexual exploitation, the Sentinela Project started to be considered a methodological framework of assistance.

Still in 2006, with the Implementation of the Uni-

28 HECLO, H. (1978). Issue Networks and Executive Establishment. In: king, A. The new American Political System. Washington: American Institute for Public. Policy Research.

29 CORTES, S.V. Enabling participation in municipal Public Policy Councils: institutional framework, organization of the popular movement and policy communities. In: HOCHMAN, G. ARRETCHE, M. MARQUES, E. (Org.) (2012). Public Policies in Brazil. Rio de Janeiro: Fiocruz. 
fied Social Assistance System (SUAS), the program started to be incorporated by it, and reached about 1,104 Brazilian municipalities, being extinguished by the Ministry of Social Development and Fight against Hunger ( MDS), in which the specialized professionals who made up the units of the Sentinela Program became the CREAS unit, which started to address not only the cases of sexual violence against children and adolescents, but also from the perspective of the family matrix.

This reprogramming, which took place from the National Social Assistance Policy (PNAS), can be analyzed in the light of what was attributed as the three basic causes of the extinction of a public policy: 1 . The problem that originated the policy is perceived as resolved; 2 . The programs, laws and actions that acted on this policy are perceived as ineffective; 3 . The problem, although not solved, has gradually lost importance and left the political and formal agendas. ${ }^{30}$

Approaching and bringing these parameters, it is clear that the third cause is the one that comes closest to explaining the extinction of that program, so, therefore, its resources were redirected to another public policy design, a fact that has been since the extinction of the program. Sentinela Program in specialized care, and in networks, children and adolescents in situations of sexual violence, as foreseen in the plan, did not have so much evidence in sectoral policies.

Even though we saw progress in implementing a national EVSCA policy in the 2000s, the evaluation of the plan proved to be a difficult task to carry out. And for that, we have as a record the Monitoring Report 2003-2004, carried out by the National Committee for the Eradication of Sexual Violence against Children and Adolescents (2006), which presented an effort to systematize, but still far from representing the evaluation as an institutionalized practice.

It should be noted that the evaluation and monitoring were not included as strategic axes of the National Plan. Evaluation is generally taken as one of the last stages of the public policy cycle, at which time the entire planning and implementation process is examined, aiming to better understand the state of the policy and the level of problem reduction that generated it. ${ }^{31}$

Regarding what has been discussed so far, it indicates a strong mobilization of governmental, nongovernmental institutions and civil society itself, in order to fight against the sexual abuse and exploitation of children and adolescents in Brazil, as well as the entire research apparatus that needs to be developed when carrying out a public policy for this

\footnotetext{
30 SECCHI, L. (2010). Public policies: concepts, analysis schemes, case studies. São Paulo: Cengage Learning. 31 Id.
}

purpose.

The initiative to build a National Plan that could guide the conduct of all states in the country, opens the door to changes, be it in making the problem of violence public, or in mobilizing diverse resources for its real confrontation based on public policies. However, it is essential to analyze some points that can be considered, discussed and questioned. This Plan, like several others that make up the scope of public policies, is operationalized through state, municipal plans to confront violence, in which the reality of this situation occurs in what way comprehensive care is provided for children and adolescents, in the municipalities that are still underway. without an adequate assistance network. It can be said that although the Plan is highly comprehensive, the National Plan does not point out ways to make judgments about the assistance to the perpetrators of sexual violence, about the prioritization of victims, and family members in their health programs.

\section{Sexual Violence against Children and Ado- lescents: the construction of indicators on violence. abntex 2}

Violence against children and adolescents has historical roots, as they were seen as adults and childhood did not exist. Work was not considered as exploitation, but as a legitimate activity in the composition of family income. Infanticide was not a crime and illegitimate or disabled children were discarded or abandoned in homes.

It was only in 1924 that the first international legislation to guarantee rights and special protection for children and adolescents (Geneva Declaration ${ }^{32}$ ) . Public policies to protect these rights will be independent of any race, nationality or belief, and should be placed in the conditions to develop in a normal way, whether moral or material.

A few decades later, the Universal Declarations of Human Rights (1948) ${ }^{33}$ and the Declaration of the Rights of Children were approved, and they are recognized as subjects of law needing special protection and care, including appropriate legal protection.

Violence of any kind against children and adoles-

32 This was the first reference to the rights of the child in
an international legal instrument dating from 1924 when
the Assembly of the Society of Nations adopted a resolu-
tion endorsing the Declarations of the Rights of Children
promulgated the previous year by the International Child
Protection Council (Save the Children International Union
), a non-governmental organization. Under the terms of
the Declaration, members of society are called upon to be
guided by the principles of this document, which has come
to be called the Geneva Declaration.
Adopted and proclaimed by Resolution No. 217 to the Third
United Nations General Assembly on December 10,1948 .

Analysis of the performance of public policies in Brazil 
cents is a power relationship in which actors, forces with unequal weight / powers, knowledge, strength of authority, experience and maturity are present and confronted. ${ }^{34}$

When a particular public policy is elaborated in an attempt to resolve the question presented, it is necessary that several analyzes be made, mainly with regard to violence; it is more easily present in the economically disadvantaged classes, due to the precarious conditions of survival, caused by the poor distribution of income, the acceleration of the urbanization process, migration, poverty, and finally, the ineffectiveness of the social policies previously implemented .

In this context, children and adolescents are included as victims of an economic-social structure of inequalities, which in addition to being considered an object of domination by adults, suffer from violence and are present in the lives of these people, whether as aggressors (adolescents), either as victims (children).

This violence is reproduced in structures and in different spaces such as in the family, at school, in the community, at work and in institutions, and when implementing public policies other factors are considered such as Brazil's territorial dimension and demographic density. , because the situations of vulnerability present themselves in different ways in each Brazilian region.

In fact, family violence is the most recurrent. In 2015 , Dial 100 recorded 40.06 percent of reports of violence against children and adolescents, whose relationship with the victims were their mothers, and another $18.16{ }^{35}$ percent were their parents and the factors that trigger the aggressions is negligence, resulting from the lack of preparation for the fatherland power, as well as the lack of basic care for the child.

Regarding physical violence and mistreatment, they are often used as coercive and educational measures by parents or guardians, while psychological violence is associated with psychological threats, causing the development of destructive behavior due to the devaluation that children and adolescents have. suffer.

In this way, the National Plan to Combat Sexual Violence against Children and Adolescents (EVSCA), BRAZIL 2013, adopted the systematic conceptual line, that is, working with sexual violence as a macro concept that involves two expressions: sexual abuse and sexual exploitation, being that the idea is to assume the existence of important characteristics in each one of them, and that these differences need to

\footnotetext{
34 FALEIROS, V.P; FALEIROS, E.S. (2007). Protecting School: facing violence against children and adolescents. Education for All Collection, n. 31. MEC / SECADI. Brasilia DF. 101p.

35 See Chilhood Brasil's Glossary of Sexual Violence. Available
} at www.childhood.org.br have an impact on protection policies.

Therefore, sexual violence is expressed in two ways, sexual abuse and sexual exploitation, and every act of any nature is an attack on the human right to the sexual development of children and adolescents, practiced by an agent in a situation of power and of unequal sexual development. in relation to children and adolescents.

We can list sexual abuse in two different ways: first, sexual abuse itself, as the use of the sexuality of a child or adolescent for the practice of any act of a sexual nature, a fact usually practiced by a person with whom the child or adolescent has a relationship of trust, and who participates in their coexistence, this violence can be intra-family or extra-family (outside of it); second, the sexual exploitation of the use of children and adolescents for sexual purposes, measured by profit, valuables, or other elements of exchange.

In terms of evidence, it is defined as sexual exploitation can thus be described, as being the most commercial context of sexual exploitation, usually involving a network of recruiters, facilitators and people who benefit from sexual exploitation.

Differently, while sexual pornography, being the reproduction, sale, exhibition, distribution and commercialization of pornographic materials. In addition to trafficking for the purpose of sexual exploitation, being the facilitation of entry or exit or displacement in the national territory.

And, finally, sexually motivated tourism, the sexual exploitation of children and adolescents by visitors from a foreign country or tourists from the country itself. The historical invisibility about sexual violence against children and adolescents is intrinsically linked to cultural factors that have been established throughout the development of Brazilian society, and the family organization, which is heavily influenced by the patriarchal model and the male-dominated conception, in which women and children come to be considered as properties. Among the various forms of manifestation of violence, sexual violence is one of the most serious, as it causes physical, emotional and sexual damage.

Kendall-Tacket, William and Finkelhor in 1993 analyzed studies on the implications of sexual abuse and decomposed these effects according to pre-school (0 to 6 years) and school ( 7 to 12 years) ages, in which they were completed by authors that there are symptoms common to the three phases: nightmares, depressions, disorders, aggression and regressive behavior. ${ }^{36}$

Research carried out through consultancy conducted by Santos (2009) on sexual exploitation in eight

\footnotetext{
36 CERQUEIRA-SANTOS, E. (2009). Victims of Sexual Exploitation: Analyzing Risk and Protection. Report Technician. São Paulo, Childhood, $120 \mathrm{p}$
} 
states $^{37}$ found that the damage suffered is profound, among the most significant data obtained are:

a. 60.0 percent of those who have already thought about suicide, and 58.1 percent have actually tried against their own lives. This percentage is more than ten times higher than that reported by young people at risk in Brazil.

b. Only 29.0 percent expressed concern about this trend.

c. About 30.0 percent of the participating girls have already experienced at least one episode of unwanted provoked abortions.

d. One third of the participants stated that they had stopped studying due to pregnancy and 21.7 percent stated that they were expelled from home.

Facing this violence requires cultural and real changes together with the combination of public policies built with society and public authorities and all spheres of the Federation.

Therefore, it is necessary to consider sexuality as a dimension to be protected for child development ${ }^{38}$, far from the oppression of violence.

Some of these analyzes of the consultancy on care will be based on research that used data from the Unified Health System (SUS), referring to care for violence, whose notification of domestic sexual violence or other violence is recorded in the Notifiable Diseases Information System (SINAN). These data supported another research on violence against children and adolescents carried out by Waiselfisz. ${ }^{39}$

Rape is the most frequent type of sexual violence that requires care, in 2011 it concentrated 59.0 percent of the total number of cases of reported sexual violence, with a higher incidence in the range of 10 to 14 years of age with a rate of 7 visits for each 100 thousand children and adolescents in this age group.

Second, with 19.2 percent of visits, comes sexual harassment, where the highest attendance rates were also recorded in the range of 10 to 14 years old, in second place, in the range of 5 to 9 years old.

The dimension of sexual exploitation in Brazil is certainly much greater than the percentages recorded

37 From a total of 110 interviews, the participation of 69 BA, SP, MT and RS), victims of sexual exploitation, aged for the protection of children and adolescents and care for them in their first 6 years of life. It involves ensuring family and community life, as well as interventions in the areas of health, education and social assistance.

39 Researcher responsible for the 2012 violence map, Children and Adolescents in Brazil, Rio de Janeiro, 2012, Flacso. pregnancy, of the total sample, 17.0 percent have already lost one or more children and natural or children and adolescents from 8 states (PA, PI, SE, RN, between 10 and 19 years and predominance of girls.

38 Child development can be understood as a set of actions

in government statistics. It is often linked to commercial sexual exploitation, human trafficking and its connections to organized crime, which highlights the difficulty of obtaining information in certain public bodies.

Another important source of data on the phenomenon of sexual violence against children and adolescents was the public policy program through Dial 100, a program created in 1997 by the Brazilian Multidisciplinary Association for the Protection of Children and Adolescents (ABRAPIA).

As of 2003, this service was incorporated into the structure of the Special Secretariat for Human Rights as instruments of public policies to confront violations of rights, the data provided for which are essential to support the definition of strategies to reduce incidences.

The evolution of Dial 100's complaints indicates a considerable increase in complaints, this performance is due to an improvement in the service over the years. Likewise, we can mention the growth of complaints of sexual violence online, on the web, with types of violations such as abuse and sexual exploitation.

It should be noted that when addressing public policies to combat sexual violence against children and adolescents, it is necessary to deal with human trafficking in border areas. This trafficking in persons is one of the illicit activities and one of the forms of human rights violations that take place on Brazil's dry borders.[40]BRAZIL (2013). National Strategy for Public Security at Borders (ENAFRON). Brasília: Ministry of Justice.

The National Public Security at Borders Strategy (ENAFRON) survey identified a relatively large number of human trafficking routes in the states that are part of Brazil's dry border area, but mainly identified that the routes follow the flow of mobility, in ways economic exploitation and are mainly driven by people's vulnerability.

But Brazil has an interesting characteristic that makes it even more difficult to deal with human trafficking, in which it is found to be a country of origin, transit and destination for traffic victims and destination for victims of human trafficking.

One of the difficulties raised by the research concerns the finding that there is some difficulty for strategic actors even for the formulation of public policies to differentiate trafficking in persons for the purpose of sexual exploitation, prostitution and trafficking for purposes of sexual exploitation and even what some call "forced prostitution".

Urges to realize that the implementation of public policies in the face of this brief scenario presented, it is essential to analyze all these exposed data so

Analysis of the performance of public policies in Brazil 
that, from there, it is possible to outline strategies for the next policies to confront violence against children and adolescents, hence the paramount importance to deal with the indicators on this violence.

Since the construction of the indicators in politics is a transdisciplinary task, as indeed the intervention itself in the question analyzed. This construction is not isolated from a specific conception of the issue and the process of articulation to combat this violence.

Pierri Cliche defines an indicator as the statistical measure of a concept or of a dimension of a concept or part of it, based on a previous theoretical analysis and integrated with a system of similar measures serving to describe the effectiveness of public policies. ${ }^{41}$

In the author's opinion, the quantitative character of the construction of indicators is emphasized, but linked to a theoretical conception, which distinguishes it from a simple social statistic. In this context, we verify that this construction is not neutral and implies an acceptance of a certain paradigm.

The author continues, placing in his discourse the considerations about the construction of the indicators the normative school, admitting that part of the values of the objective school is based on the physical observation of the situation, as it is the subjective school linked to the perception of the situation by its subjects.

The role of indicators in this scenario is quite broad and can serve to describe situations, social accounting, assess public policies themselves, as well as plan actions.

It is important, however, to emphasize that the construction of indicators is a complex theoreticalpractical process, it is not enough to raise isolated characteristics of any theme, without the proper foundations and articulations. In this area, the construction of indicators based on guaranteeing the rights of children and adolescents, as proposed by the Ministry of Justice system, is part of the paradigm of comprehensive protection and considers violence as any violation of the rights provided for in the Statute of Children and Adolescent.

In addition, the records of the described violations made available through statistical accounting and diagnosis of the situation of the child and adolescent, and of parameters, will serve to evaluate the civilizing paradigm of guaranteeing these rights. Comprehensive protection is both a process and a result, which therefore requires indicators.

For the elaboration of research on violence, there are concepts that are fundamental in power relations, which can be detailed from the in-depth studies of

41 CLICE, Pierri (1975). Sociauxe indicators: conceptions et elaboration. Quebec. intrafamily and exploitation situations. For, it combines at the same time, the analysis of situations and the manifestation of subjectivities of abusers and victims.

From a perspective of interaction between subject, family and society, Sílvia Koller has contributed to the construction of risk situation indicators, which can be considered objective and subjective. The risky situations here include the family, the degree of culture and the form of relationships with the child.

In reference to the level of the subject and the child, the author admits that they are all considered as risk factors: the children's ability to react, their level of understanding and their education, being a systemic and integrated conception.

For the elaboration of social policies, in this area, it is necessary to move in the direction of articulating the fight against violence with the dismantling of violence, and in this case, the fight can be measured by the number of responsible abusers, the decrease in complaints and the number of victims attended with resoluteness.

Therefore, the dismantling of violence is a complex process that involves trained personnel, articulated teams, built networks, authoritarian culture, modified happy and happy children, responsible families in the fulfillment of their functions, in the formation of identity, protection and socialization.

According to Bonnefoy; Armijo, 2006, among the basic functions that the indicators can have, two can be highlighted: the descriptive function and the evaluative function. The descriptive function that consists of information about a given public action, whereas the evaluative function, involves aggregating information from value judgments, with a view to verifying the relative importance of a particular problem, or whether the performance of that program is adequate or not.

It is very true, because both for social research and for the performance and implementation of public policies, plans and programs are consistent with the indicators and appear as a mediation between theories and evidence of reality, generating instruments capable of identifying and measuring some type of social phenomenon.

In addition, according to Garcia, due to basic functions, the indicators are widely used for the implementation, planning and evaluation of programs, for which it is necessary to know what are the aspects of the program, and to have indicators for each one of them, in the case under analysis when addressing sexual violence against children and adolescents.

Finally, it is unnecessary to address the types of indicators with specifics or enumerations, because they 
are classified in a very varied way in the specialized literature, as well as their perspectives of use, whether from the point of view of the social sciences or the point of formulation, or very less the analysis of social programs and policies, extensively addressed by researchers and government entities.

\section{FINAL CONSIDERATIONS}

The analysis of the present article had as main goal to explain the formal agenda adopted by the public power, indicating that the National Plan to Combat Violence against Children and Adolescents was a watershed in the period in which it became a reference in the policy to be implemented throughout Brazil for all sectors and social segments.

It was observed, then, that the National Plan was an important one for the analysis of how the EVSCA policy was being outlined and implemented in its different phases as a cycle of public policies, the definition of problems and the agenda, going through the implementation until reaching its evaluation and redefinition. This allowed us to recognize obstacles and limits for the implementation of public policies.

It remains for us to clarify that all these phases were marked by influences from organized groups of civil society, which forged a shared management with the public power of the institutionalized decision processes and channels.

The movement that culminated in the agreement with the National Plan, involved the different actors of the public power, civil society and multinational organizations in the deliberative processes, and later, in the collegiate management spaces, like the EVSCA National Committee and the Commission EVSCA intersectoral.

Therefore, the strategies for implementing and agreeing on public policies to face sexual violence against children and adolescents in situations of high social vulnerability from an intersectoral, interinstitutional point of view bring together the complementarity of knowledge, interdisciplinarity and integral performance in Rede Nacional e Regional and Local subnets, with children and adolescents at the center, from the perspective of comprehensive protection, their real social insertion, through education, social assistance, health and cultural projects.

The same can be observed at the international level in relation to the role played by transnational NonGovernmental Organizations (NGOs), as we emphasize that the mutual influence of national and international agendas; movement that feeds back in that period and that had the world congresses and the campaigns as drivers of this confluence.

Even recognizing the importance of the National Plan as a public policy of great breadth and historical landmark in the confrontation of sexual violence against children and youth, the problem that gave rise to it is far from this scenario and in view of these difficulties to be overcome.

Countless factors limit its implementation, highlighting the budgetary aspects and those of institutional structures responsible for its execution. Notwithstanding, interinstitutional coordination efforts, it is still necessary to advance in the perspectives of public policy network management focused on complex or extensive problems.

In this context, at the end of 2000, CONANDA turned to the discourse of the National Policy for the National Combat of Violations against Children of Adolescents, and the 10-year Plan where for the first time a unified national policy on the human rights of children and adolescents was widely discussed Brazil.

Historically, this policy constitutes the logic of coping with the various modalities of violation of rights, in the form of fragmented thematic public policies. For, in addition to the theme of sexual violence, we can mention other examples of themes that would constitute public policies and plans such as: child labor, drug use, abandonment, and institutionalization of children and adolescents.

In spite of everything explained here, the progress in this perspective is still incipient and without the necessary resources for the implementation of an integrated and intersectoral policy, which considers the child and adolescent as a subject of rights and not only as a victim of violations.

For the confrontation and sexual exploitation and the protection of fundamental rights that hold the universality of children and adolescents, the development of public policies at the national level is extremely important. Given that the Statute of Children and Adolescents provides for a series of public policies to guarantee the rights and protection of children, which are interdisciplinary and which must act in an articulated and networked manner, decentrally.

Thus, the public care policies planned by the Council for the Rights of Children and Adolescents, a body present at the national, state and municipal levels, are responsible for the care of children and adolescents, enabling the guarantee of rights to health, education, social assistance, culture to sport and other basic social rights, through public agencies that should have their employees working in the identification and notification of the occurrence of sexual violence, in order to make it possible to face the situation of sexual violence that occurred in the Brazilian territory.

The protection policies that are implemented by the Guardianship Councils and the Public Prosecutor's Office are intended to guarantee the full protection

Analysis of the performance of public policies in Brazil to cope with sexual violence against children and adolescents 
of children and adolescents for the application of the various protection measures disciplined in the Statute of Children and Adolescents (ECA). To this end, the provision in the caput of Article 227 of the 1988 Federal Constitution, which deals with the protection of children in an integrated manner between family, state and society, was considered as essential.

According to which, the family as the primary function of educating, must insert the minor in the social sphere, and society, by itself, has a duty to care for the common good. Having verified that the role of the State is of paramount importance for the creation and implementation of public policies that have the purpose of protecting and supporting victims of sexual abuse, and should also protect the post-aggression treatment, with the objective of repair damage.

The violence suffered by individuals who are in a situation of vulnerability and social exclusion brings harmful results to the individual caused by the violence suffered, which directly interfere in the development of the subject. In this sense, public coping policies must preserve the principle of "promoting, defending, and control the enforcement of civil, political, economic, social and cultural rights ..." both those who have had their rights violated and those who are in a situation of social vulnerability.

In this sense, the care policy is exactly to respond to these different situations of violence and contexts of social vulnerability, generating flows of care integrated into the network, policies and intersectoral services in the territories so that it can thus resolve.

In view of the above, it is concluded that it is of great importance for public policies that the indicators are defined, primarily based on the real needs identified, as close as possible to the desires of society.

Thus, in this succession of steps, programs must focus on their objectives and goals and the consequent allocation of resources based on the policy indicators that are to be implemented with indicators that clarify and enable the mediation of results in physical and financial terms. And, it is possible to optimize public spending and achieve effective results that in fact cause a qualitative change for the public to which it is destined.

\section{REFERENCES}

ANANIAS, P. (2010). On the Duty to Change Reality: the role of the State in promoting social public policies in a model of integral development. In: Social policies for development: overcoming poverty and promoting social inclusion. COELHO, M.F.P; TAPAJÓS, M. S; RODRIGUES, M. (Org.). Brasília: Ministry of Social Development and Fight against Hunger, UNESCO, 360p.
AZAMBUJA, Maria Regina Fay de (2004). Intrafamily Sexual Violence: Is it possible to protect our children? 1. ed. Porto Alegre: Livraria do Advogado.

AZEVEDO, M. A. (1998). Psychological consequences of the victimization of children and adolescents. In: AZEVEDO, M. A; Guerra, V.N.A (Org.). Victimized children: the small power syndrome. São Paulo: Iglu p. 143-167.

BERNSTEIN, Brasil (1996). The structuring of class, code and control pedagogical discourse. Petrópolis: Editora Vozes.

BITTENCOURT, C.B.F. (1995). Sexual violence against children and adolescents: psychological implications. Modern Pediatrics. São Paulo, VXXXI, n 3, p.420-424.

BONETTI, Lindomar. Wessler(2007). Public Policies inside. Ijui: Ed. Unijui.

BOURDIEU, P. (1989) Symbolic power. Ed. DIFEL, Portugal.

BRAZIL (1988). Federal Constitution of the Republic of Brazil. Brasília: National Congress.

BRAZIL (1990). Law No. 8,069/1990. Child and Adolescent Statute. Updated version. Brasília: National Congress. nineteen ninety.

BRAZIL (2004). Final Report of the Joint Parliamentary Commission of Inquiry on violence and sexual exploitation networks for children and adolescents in Brazil. Brasília: National Congress.

BRAZIL (2012). National Council for the Rights of Children and Adolescents (CONANDA). Resolution $\mathrm{n}^{\circ} 152$ of August 9, 2012. Brasília: SECRETARY OF HUMAN RIGHTS OF THE PRESIDENCY OF THE REPUBLIC.

BRAZIL (2013). National Strategy for Public Security at Borders (ENAFRON). Brasília: Ministry of Justice.

BRAZIL (2013). National Plan to Combat Violence against Children and Adolescents. Brasília: Ministry of Human Rights, 2013. Available at http://www.crianca.mppr.mp.br/arquivos/File/pu bli/sedh $/ 08_{2} 013_{p}$ nevsca.pdf.

BRAZIL (2018). National Program to Combat Sexual Violence against Children and Adolescents. Program of integrated actions and References for Coping with Sexual Violence against Children and Youth in Brazilian territory. Brasília: SDH-PR.

BRAZIL (2018). Final Report of the Joint Parliamentary Commission of Inquiry on violence and sexual exploitation networks for children and adolescents. Brasília: SEDH, PR.

BUCCI, Maria Paula Dalllari. (2006) The concept of Public Policies in Law. In: Public Policies: reflections 
on the legal concept. São Paulo: Saraiva, p. 1-50, p.39.

CARDOSO, A. L. (1998). Social and public policy indicators: some critical notes. Proposal No. 77. Brasília: Ministry of Human Rights, June-August.

CERQUEIRA-SANTOS, E. (2009). Victims of Sexual Exploitation: Analyzing Risk and Protection. Report Technician. São Paulo, Childhood, 120 p.

CHILD WELFARE INFORMATION GATEWAY (2003). Emerging practices in the prevention of child abuse and neglect. Washington DC.: Office on child Abuse and Neglec. Available at http://www.childwelfare.gov/preventing/programs /whatworks/report/emerginga.cfm Accessed on: December 14th. 2007.

CLICE, Pierri (1975). Sociauxe indicators: conceptions et elaboration. Quebec.

CORTES, S.V. Enabling participation in municipal Public Policy Councils: institutional framework, organization of the popular movement and policy communities. In: HOCHMAN, G. ARRETCHE, M. MARQUES, E. (Org.) (2012). Public Policies in Brazil. Rio de Janeiro: Fiocruz.

BUCCI, M. P. Dallari (2006). Public Policies. Reflections for a legal concept, Ed. Saraiva. Santos: UNISANTOS, SP.

DALLARI, D. de A. (2013) Elements of general theory of the State. 32. ed. Rio de Janeiro: Saraiva.

DIAS, Reinaldo; MATOS, Fernanda (2012). Public policies: principles, purposes and processes. São Paulo: Atlas.

DUARTE, Clarisse Seixas (2013). The Public Policy cycle. In: Bertolinni, Patrícia Tuma Martins; SMANIO, Gian Paulo Paggio. (Org.). Law and Public Policies in Brazil. Sao Paulo; Atlas, 2013, p.16-43. p.26.

FALEIROS, V.P; FALEIROS, E.S. (2007). Protecting School: facing violence against children and adolescents. Education for All Collection, n. 31. MEC / SECADI. Brasilia DF. 101p.

FLEURY, Afonso; FLEURY, Maria Tereza Leme (2007). Business strategies and skills formation: a kaleidoscopic puzzle of Brazilian industry. São Paulo.

FONSECA, Paulo Cesar Dutra; MONTEIRO, Sergio Marley Modesto (2008). The state and its reasons: The II PND. Political Economy Magazine. v. 28. N. 21. São Paulo, Jan / Mar.

GARCIA, R. C. (2001). Grants for organizing evaluations of government action Planning and Public Policies. Brasilia, v. 23, p. 70.

GAUDERER, E. C.; MORGADO, K. (1992). Sexual abuse in children and adolescents. Journal of
Pediatrics. Porto Alegre, vol. 68, n. 7/8, p. 243-247. HAM, Cristopher; HILL, Michael (1993). The policy making process in the modern capitalist state $(\mathrm{R}$. Amorim; R. Dagnino, Trad.). Adaptation and revision: Renato Dagnino. Campinas- SP: Editora da Unicamp.

HECLO, H. (1978). Issue Networks and Executive Establishment. In: king, A. The new American Political System. Washington: American Institute for Public. Policy Research.

KINGDON, John W (2011). Agendas, Alternatives and Public Policies. 2nd Edition (magazine). Boston: Longman.

KOLLER, Silvia (1998). Sexual violence against children and adolescents and the construction of indicators: the critique of power, inequality and the imaginary. Lecture given at the Catholic University of Brasilia. Brasília, SER SOCIAL, UnB. DOI http://doi.org/10.26512/ ser $_{s}$ ocial.v0i2.12842

MONTEIRO, Jorge Vianna (2006). The policymaking process. In: SARAIVA, Enrique; FERRAREZI, Elisabete, Org. Public Policies: Collection. Brasília: ENAP, Chap. 4, v.1, p.269-288. Available at: http // www.enap.gov.br / index. Accessed on: $12 / 152019$.

MULLER, P. (2002). Las public policies. Colombia: Universidad Externado de Colombia.

PINTO, Isabella Cardoso de Matos (2008). Change in Public Policies: the perspectives of the public policy cycle. Public Policy Review. São Luís, v.12, n 1, p.27-36, jan./jul. Available at: http//www.periodicoeletronicos.ufma.br/index.php /Republi.

RAMOS, Marília Patta; SCHABBACH, Letícia Maria (2012). The state of the art of public policy evaluation conceptualization and examples of evaluation in Brazil. Journal of Public Administratio, Rio de Janeiro., V. 46, n 5, p 1271-1294, sep/oct.

SARAIVA, Enrique (2006). FERRAREZZI, Elizabete (Org.). Public policy. Brasília: ENAP. Available at: http // repositório.enap.gov.br / bitstream / handle / 1/1254 / saravia.pdf /. Accessed on 02/14/2017.

SEN, Amartya. Development as freedom. São Paulo: Companhia das Letras, 2000.

SECCHI, L. (2010). Public policies: concepts, analysis schemes, case studies. São Paulo: Cengage Learning.

SOUZA, Celina (2006). Public Policies: a literature review. Sociologies, Porto Alegre, year 8, n 16,P. 20, 45Jul / Dec. Available at: htpp / www.scielo.br / pdf / soc / n16. Accessed on: April 11, 2014.

SUREL, Ives. (2008). Public policies as paradigms Public Policies as Paradigms Political studies.

Analysis of the performance of public policies in Brazil to cope with sexual violence against children and adolescents 
Trad. Javier Sanchs Segura. Estudios Politicos, n 33, Medellin/Colombia, julio-diciembre de 2008, pp.41-65. ISSN 0121-5167. available in: http://bibliotecavirtual.clacso.org.ar/Colombia/iepudea/20100622031542/RevistaCom pleta33.pdf

UNITED NATIONS ORGANIZATION (1989). Convention on the Rights of the Child, adopted on November 20 .

WIEWIORKA, Michel (1997). "The new paradigm of violence". In: Tempo Social, n 41, São PAULO, USP. 